\title{
The Short-Term Effectiveness of a Suicide Prevention Gatekeeper Training Program in a College Setting with Residence Life Advisers
}

Tanya L. Tompkins

Linfield College

Jody Witt

Linfield College

Follow this and additional works at: https://digitalcommons.linfield.edu/psycfac_pubs

Part of the Mental and Social Health Commons

\section{DigitalCommons@Linfield Citation}

Tompkins, Tanya L. and Witt, Jody, "The Short-Term Effectiveness of a Suicide Prevention Gatekeeper Training Program in a College Setting with Residence Life Advisers" (2009). Faculty Publications.

Accepted Version. Submission 4.

https://digitalcommons.linfield.edu/psycfac_pubs/4

This Accepted Version is protected by copyright and/or related rights. It is brought to you for free via open access, courtesy of DigitalCommons@Linfield, with permission from the rights-holder(s). Your use of this Accepted Version must comply with the Terms of Use for material posted in DigitalCommons@Linfield, or with other stated terms (such as a Creative Commons license) indicated in the record and/or on the work itself. For more information, or if you have questions about permitted uses, please contact digitalcommons@linfield.edu. 
Running head: GATEKEEPER TRAINING IN A COLLEGE SETTING

The Short-Term Effectiveness of a Suicide Prevention Gatekeeper Training Program in a College Setting with Residence Life Advisers

Tanya L. Tompkins ${ }^{1}$ and Jody Witt Linfield College

${ }^{1} 900$ SE Baker Street, A570 McMinnville, OR 97128

Phone: 503-883-2684

Fax: 503-883-2669

tatompki@linfield.edu 
Author Note

Tanya Tompkins and Jody Witt, Department of Psychology, Linfield College

This research was supported by a student/faculty collaborative research grant from Linfield College. This research was Jody Witt's honor's thesis and a portion of the current study was previously presented at the meeting of the Association for a Psychological Science in May, 2007. We gratefully acknowledge Nadia Abraibesh and Jee-Yeon Kim for their assistance with data collection and entry. We also thank Christina Ries and Kristen Michael for providing the QPR training. Finally, we extend our deepest appreciation to the residence life administrators and staff members for their willingness to participate and help us understand the effectiveness of QPR.

Correspondence concerning this article should be addressed to Tanya L. Tompkins, Department of Psychology, Linfield College, 900 SE Baker Street, A570, McMinnville, Oregon 97128. E-mail: tatompki@linfield.edu.

\footnotetext{
${ }^{1} 900$ SE Baker Street, A570 McMinnville, OR 97128

Phone: 503-883-2684

Fax: 503-883-2669

tatompki@linfield.edu
} 


\begin{abstract}
Although the college years prove to be a vulnerable time for students and a critical period for suicide prevention, few school-based prevention strategies have been empirically evaluated. The current study examined the short-term effects of QPR (Question, Persuade, and Refer), a gatekeeper training program that teaches how to recognize warning signs, question suicidal intent, listen to problems, and refer for help. The 122 residence advisers (RAs) who were trained in QPR demonstrated significant post-training gains across a variety of domains relevant to suicide and suicide prevention, with the 60 completing the follow-up assessment showing sustained knowledge and appraisals into the following semester. Although these gains were generally more substantial for RAs trained in QPR, 86 controls who completed both baseline and follow-up assessments also demonstrated changes in appraisals relevant to suicide and suicide prevention, despite having not received QPR training. The need for replication, policy implications, and suggestions for a multifaceted approach to suicide prevention within the college setting are discussed.
\end{abstract}

Keywords: suicide prevention, gatekeeper training, empirical evaluation, college students

${ }^{1} 900$ SE Baker Street, A570 McMinnville, OR 97128

Phone: 503-883-2684

Fax: 503-883-2669

tatompki@linfield.edu 
The Short-Term Effectiveness of a Suicide Prevention Gatekeeper Training Program in a College Setting with Residence Life Advisers

Nationally, suicide is the third leading cause of death among 18- to 24-year-olds (Centers for Disease Control [CDC], 2005). Although estimates of other suicidal behavior including serious ideation and/or attempts vary across studies (Furr, McConnell, Westefeld \& Jenkins, 2001; Westefeld et al., 2005) data from the most recent National College Health Assessment (NCHA) suggest that approximately $16 \%$ of the 20,057 college students surveyed reported being diagnosed with depression, $10 \%$ seriously considered suicide, and just under $2 \%$ reported attempting suicide within the past 12 months (American College Health Association [ACHA], 2008). In response to the enormity of the problem, the National Strategy for Suicide Prevention (United States Public Health Service) was drafted in 1999, and called for a broad-based initiative to promote protective factors and reduce suicide and suicidal behaviors. In light of this recent attention, as well as the broader harm that befalls friends and family when suicides occur, it is surprising that so few school-based programs have been evaluated for effectiveness, particularly within the college setting (Joffe, 2008; Mann et al., 2005). The current study seeks to empirically evaluate the use of a gatekeeper training suicide prevention program with residence life advisers (RAs) as they are viewed as peers in the first line of defense in the college setting (Westefeld et al., 2006).

Why Are Students at Risk?

There are various reasons why college-aged adults may be at heightened risk for experiencing suicide ideation, attempts and completions. Westefeld and colleagues (2006)

${ }^{1} 900$ SE Baker Street, A570 McMinnville, OR 97128

Phone: 503-883-2684

Fax: 503-883-2669

tatompki@linfield.edu 
describe the shift from adolescence to college as a major life transition that is multifaceted in nature, leading to shifts in students' social, academic, psychological, and existential selves. For instance, the college years are often the first experience of distance from parents and close friends, which, for some, can cause distress (Westefeld et al., 2006). During the transition from high school to college, many students are exposed to substance/alcohol use, a significant risk factor for suicidal behavior (Barrios, Everett, Simon \& Brener, 2000; Brener, Hassan, \& Barrios, 1999; Conner \& Goldston, 2007; Weitzman, 2004; Westefeld et al., 2006). Finally, age of onset for psychological conditions commonly associated with suicidal ideation and attempts typically have their onset between the ages of 18 and 24 and several sources (self-report, counseling director perspectives, insurance claims) have drawn attention to the observation that there are a growing number of college students with serious psychological problems and an increase in the number of students seeking counseling (Benton, Robertson, Tseng, Newton, \& Benton, 2003; Kitzrow, 2003; Voelker, 2003). For example, student self reports reflect growing mental health concerns. In 2007, when students were asked to report the top 10 health impediments to academic performance, seven of the obstacles bore some relationship to potential mental health concerns, including stress, depression/anxiety/sadness, and relationship difficulties (ACHA, 2008). Additionally, the number of students ever being diagnosed with depression has increased from $10 \%$ in fall 2000 to $16 \%$ in fall 2007 (ACHA, 2001; 2008), with some studies demonstrating even higher rates of depression (e.g., Furr et al., 2001).

Those charged in the college setting with addressing student mental health needs also perceive a recent surge in mental health concerns (Gallagher, Zhang, \& Taylor, 2004). Most of the college counseling center (CCC) directors surveyed during the most recent National Survey

${ }^{1} 900$ SE Baker Street, A570 McMinnville, OR 97128 Phone: 503-883-2684

Fax: 503-883-2669

tatompki@linfield.edu 
of Counseling Center Directors, conducted by the Association of University and College Counseling Center Directors (AUCCCD) and the American College Counseling Association (ACCA), reported a belief that in recent years there has been an increase in the number of clients with severe psychological problems $(87 \%)$, that students with significant psychological disorders are a growing campus concern $(91 \%)$, and that more students $(92 \%)$ are coming to counseling already on a psychotropic medication (Gallagher et al., 2004). The growing number of students who are entering college with pre-existing mental health problems may represent a group at heightened risk for adequately coping with the increased academic, social, psychological and financial demands that, at times, may accompany student life. Finally, utilization data also point to increasing use of college counseling center services as outpatient mental health claims per covered student rose an average of $64 \%$ over a 4-year period from 1999 to 2003 (Kaplan \& Reed, 2004).

Despite the unique risk factors college students face, some researchers argue higher risk in this age group among those who do not attend college (Haas, Hendin \& Mann, 2003). For example, Silverman, Meyer, and Sloane (1997) examined the suicide rate across a ten-year period in the Mid-Western states and found that among college students the rate was 7.5/100,000 compared to the national rate of $15 / 100,000$. Although the number of students who kill themselves on any given college campus in a given year is relatively low, extrapolating from the 17.5 million students enrolled in private and public institutions in 2005, a staggering number of students take their own lives (U.S. Department of Education, 2008). This loss is unacceptable given that college communities, with their social structure and available resources, provide an ideal setting in which to prevent suicide (Joffe, 2008).

${ }^{1} 900$ SE Baker Street, A570 McMinnville, OR 97128 Phone: 503-883-2684

Fax: 503-883-2669 tatompki@linfield.edu 


\section{Prevention in the College Setting}

Data regarding suicidal ideation and attempts suggest that a minority of students who attempt or complete suicide have sought counseling prior to the suicidal crisis (Furr et al., 2001; Gallagher et al., 2004). Several recent studies, two conducted among younger populations, suggest that vulnerable youth at risk for suicide may be reluctant to seek help. For example, Gould, Greenberg, Munfakh, Kleinman and Lubell (2006) found that only $2 \%$ of youth reported using crisis hotlines, with barriers to use being strongest amongst youth experiencing impairment and hopelessness. Similarly, Wyman and colleagues reported that less than one fifth of $8^{\text {th }}$ and $10^{\text {th }}$ graders with a recent attempt reported that they would seek out help from an adult in the school setting (Wyman, Brown, Inman, Cross, Schmeelk-Cone, Guo et al., 2008). Finally, Garlow and colleagues (2008) found that the majority of college students with moderately severe to severe depression $(85 \%)$ or current suicidal ideation $(84 \%)$ were not receiving current treatment (Garlow et al., 2008). Given reticence to self-refer, it is imperative that others are prepared to respond to signs of depression and suicidality and persuade them to seek help.

Evidence suggests that suicidal youth and young adults may turn to their peers first (Aseltine \& DeMartino, 2004; Kalafat \& Elias, 2001; Ross, 1980). Importantly, Lawrence and Ureda (1990) suggest that freshman college students were able to recognize suicidal behavior but were unsure how to intervene in a helpful manner. Considering that peers are more likely to be aware of suicidal behavior in a fellow student, but perhaps ill-equipped to respond, suicide prevention strategies that teach students how to effectively recognize warning signs, question suicidal intent, listen to problems, and refer for help may be particularly beneficial.

${ }^{1} 900$ SE Baker Street, A570 McMinnville, OR 97128

Phone: 503-883-2684

Fax: 503-883-2669

tatompki@linfield.edu 
Such is the aim of gatekeeper training, a prevention strategy that improves detection and referral of at-risk individuals. Although there are limited evaluations of effectiveness for gatekeeper training programs, initial evidence is encouraging and suggests that gatekeeper training improves knowledge and attitudes (Cross, Matthieu, Cerel, \& Knox, 2007; Davis, 2001; Eggert, Randell, Thompson, \& Johnson, 1997; King \& Smith, 2000; Knox, Litts, Talcott, Feig, \& Caine, 2003; Mackesy-Amiti, Fendrich, Libby, Goldenberg, \& Grossman, 1996; Shaffer, Garland, \& Gould, 1988; Tierney, 1994; Turley, \& Tanney, 1998; Wyman et al., 2008). Unfortunately, few school-based prevention strategies, including gatekeeper training, have been empirically evaluated and most have tended to focus exclusively on younger populations (Joffe, 2008; Knox et al., 2003). Given important differences that may exist between high-school youth and college students, it remains to be seen whether prevention efforts will be as effective in the college setting (Barrios et al., 2000).

Resident Advisors (RAs) may be particularly well suited for gatekeeper training given their natural helping role and the potential ease of implementation among this group. Westefeld et al. (2006) suggest RAs are in the first line of defense against suicide in the college setting and should be educated in the warning signs of depression and suicidality. Additionally, Grosz (1990) argues that RAs are often in the best position for early intervention with a suicidal student and describes an effective training program for RAs that teaches them how to recognize verbal, behavioral, and affective signs of suicide. This model for effective training in the college setting with RAs mirrors the goals of gatekeeper training.

Question Persuade and Refer (QPR)

${ }^{1} 900$ SE Baker Street, A570 McMinnville, OR 97128

Phone: 503-883-2684

Fax: 503-883-2669

tatompki@linfield.edu 
QPR, developed by Paul Quinnet (QPR Institute, 2006), is a gatekeeper training program dedicated to teaching those in close contact with at-risk populations how to recognize warning signs of suicide, offer hope to a suicidal individual, and refer for help. QPR adheres to a public health saturation model in which the desired endpoint is that QPR will become as well known and widely used as Cardio Pulmonary Resuscitation (CPR) to enhance early detection of suicidal risk, prevent attempts and completions and thereby obviate the need for more intensive intervention. Although a randomized clinical trial of this program within secondary school staff has just recently been completed (Wyman et al., 2008) there are no published studies evaluating prevention outcomes of QPR within a college population. The Standards of Practice for Health Promotion in Higher Education released by the ACHA (2004) highlight the importance of using evidence-based practice in preventing college suicide. The current study seeks to evaluate the short-term effects of a gatekeeper training program on RAs knowledge, appraisals of their ability to perform key gatekeeper behaviors, and self-reported identification and referral of at-risk students within the college setting. It is expected that those participating in the program will demonstrate significant training gains, compared to a limited control group, in areas such as knowledge of risk factors and QPR and appraisals of their ability to enact key behaviors learned in the training, notably identification and referral of at-risk individuals. Finally, exploratory analyses will examine students' perceptions of suicide prevention, resources, and policies at their college as well as QPR participants' evaluations of the prevention program.

Method

\section{Participants}

${ }^{1} 900$ SE Baker Street, A570 McMinnville, OR 97128

Phone: 503-883-2684

Fax: 503-883-2669

tatompki@linfield.edu 
Participants included 240 college student resident advisors (RAs) from six private institutions located in the Pacific Northwest in both rural and urban settings (average size approximately 2,300 students). Participating colleges were recruited through letters, emails, and phone calls to the resident directors at the respective schools. The majority of the sample was Caucasian $(83 \%)$ and female $(59 \%)$. The mean age of participants was 20 years $(S D=1.02)$ and most were college sophomores (37\%) or juniors $(37 \%)$. Highlighting the far reaching effects of suicide, $46 \%$ of the sample reported that they had a friend, relative, parent, sibling, or other close individual either attempting or completing suicide.

\section{Measures}

The survey was adapted from similar gatekeeper evaluation studies (Organizational Research Services (ORS), 2002; Wyman et al., 2008) and inquired about demographics and a variety of other domains including knowledge, appraisals, and self-reported gatekeeper behaviors. QPR participants were also asked to evaluate the training program (see Table 1 for complete list of items and limited psychometric information). Additionally, participants' beliefs toward suicide and suicide prevention were assessed with a variety of questions rated on a 5point scale from 1 = strongly disagree to 5 = strongly agree including: "suicide among people my age is a major issue", "my college should be active in suicide prevention", and "suicide is preventable in the majority of situations".

\section{Procedure}

The present study used a quasi-experimental non-equivalent control group design with the administrators at two schools self-selecting their RAs to receive training, three opting to only complete surveys (control groups), and one school choosing to serve as a waitlist control group

\section{${ }^{1} 900$ SE Baker Street, A570 McMinnville, OR 97128}

Phone: 503-883-2684

Fax: 503-883-2669

tatompki@linfield.edu 
(with training provided after follow-up assessment). Although one of the experimental groups had significantly more sophomores serving in the RA role relative to other colleges, there were no demographic differences (e.g., gender, ethnicity, year in college) between the experimental and control groups. Additionally, each of the six participating colleges utilizes similar selection criteria and procedures (e.g., minimum GPA, application, reference, and interview) and RAs receive similar training opportunities in assuming the RA position.

Three college's residence life staffs received QPR training $(n=122)$ and completed the paper-and-pencil survey immediately before and after training. To preserve participant anonymity each participant was asked to generate a unique numeric identifier (e.g., third letter of first name, two-digit year of birth date, two-digit month of birth date, last letter of last name). The 1-hour training was taught by a QPR certified trainer who discussed prevalence of suicide among college students, risk factors for depression and suicidality, appropriate ways to ask if a student is considering suicide, and reviewed the steps that should be taken when intervening and referring a suicidal person for help. Although fidelity data were not collected in the current study, staff providing training in a recent randomized trial of QPR with secondary school staff evidenced high rates of fidelity (Wyman et al., 2008).

RAs from three other colleges served as control group participants $(n=118)$ and completed similar paper-and-pencil baseline surveys. Baseline data collection for both groups occurred just prior to or within the first month of classes beginning during the fall academic term. To alleviate participant burden, control group members were not required to complete a post-test immediately after completing the baseline measure. However, in order to evaluate possible testing effects, we invited control group participants to take an online post-test survey

${ }^{1} 900$ SE Baker Street, A570 McMinnville, OR 97128

Phone: 503-883-2684

Fax: 503-883-2669

tatompki@linfield.edu 
with only a limited number of people completing post-test surveys $(n=31)$. Attrition analyses comparing this limited group of control group participants who completed post-test surveys to controls who only completed baseline surveys suggested no significant differences in demographics or baseline levels of knowledge, appraisals, or gatekeeper behaviors. Data gathered from the limited control group participants who completed both baseline and post-test data will be used only to evaluate possible testing effects (see below).

Finally, during the first month of the spring academic term, approximately 5 months (range 4 to 6 months) after participating in the study, both control and QPR participants were asked to complete a follow-up measure assessing the same domains of knowledge, appraisals, and behaviors. A limited number of controls $(n=86)$ and QPR $(n=60)$ participants completed the follow-up, paper-and-pencil measure. We conducted attrition analyses to compare RAs that completed follow-up measures with those who did not (see below).

\section{Results}

\section{Preliminary Analyses: Group Equivalency, Testing Effects and Attrition Analyses}

Given that random assignment was not feasible, preliminary analyses were conducted to examine whether there were any pre-existing differences between the two groups. Results suggested that while there were no baseline differences in terms of demographics or self-reported gatekeeper behaviors, prior to training the QPR and control groups differed in their appraisals of

knowledge of resources. The control group participants reported having higher baseline levels of knowledge of resources, relative to QPR group participants, $t(238)=30.81, p<.001$. This variable will be used as a covariate in all analyses involving between-group comparisons.

${ }^{1} 900$ SE Baker Street, A570 McMinnville, OR 97128

Phone: 503-883-2684

Fax: 503-883-2669

tatompki@linfield.edu 
Paired sample t-tests revealed testing effects for Self Evaluation of Knowledge t(30) = $2.54, p<.05$ and for Gatekeeper Efficacy, $t(29)=-2.44, \mathrm{p}<.05$, suggesting gains in general knowledge and efficacy from pre- $(M=3.18, S D=.56 ; M=4.47, S D=.75)$ to post-test $(M=$ $3.44, S D=.51 ; M=4.78, S D=.47$ ) for our limited control group that completed both pre-and post-test measures $(n=31)$. Although testing effects were limited to appraisals about knowledge and gatekeeper efficacy, given that testing effects were found it is possible that even focusing on answering questions about suicide and suicide prevention may change self-appraisals in limited ways.

To determine whether attrition from fall to spring semester might have differentially affected QPR and control groups, we conducted a series of 2 X 2 (Group x Drop-out status) Analyses of Variance (ANOVAs). There was a significant effect of Drop-out Status, $F(1,238)$ $=4.36, p<.05$, suggesting that participants who did not complete follow-up assessment had higher appraisals of knowledge $(M=3.22, S D=.71)$ relative to those who completed follow-up $(M=3.06, S D=.68)$. However this was qualified by a significant Group x Drop-out Status interaction, $F(1,238)=5.50, p<.05$, with QPR group participant who dropped out reporting significantly higher self-appraisals of knowledge $(M=3.24, S D=.83)$, relative to QPR trained participants who completed the follow-up assessment $(M=2.84, S D=.58), t(120)=3.10, p<$ .01 ; there were no significant differences in self-appraisals of knowledge for control group participants who completed vs. did not complete follow-up assessment. A similar pattern of results was found for appraisals of Gatekeeper Efficacy, although the main effect was not significant, $F(1,239)=2.74, p<.10$. There was a significant Group x Drop-out Status interaction, $F(1,239)=5.03, p<.05$, with QPR group participant drop outs reporting

\section{${ }^{1} 900$ SE Baker Street, A570 McMinnville, OR 97128}

Phone: 503-883-2684

Fax: 503-883-2669

tatompki@linfield.edu 
significantly higher self-appraisals of Gatekeeper Efficacy $(M=4.64, S D=.99)$, relative to QPR trained participants who completed the follow-up assessment $(M=4.21, S D=.73), t(120)=$ 2.67, $p<.01$; there were no significant differences in self-appraisals of Gatekeeper Efficacy for control group participants who completed vs. did not complete follow-up assessment. There were no other differences (nor differences moderated by group status) on demographic variables, other appraisal scales, nor on self-reported gatekeeper behaviors.

\section{Students Perceptions of Suicide and Suicide Prevention}

At baseline, most students (65\%) agreed or strongly agreed that suicide among people their age was a major issue, $88 \%$ believed that their college should be active in suicide prevention, and $81 \%$ believed that suicide is preventable in the majority of situations. In addition, the majority of students endorsed that RAs should be responsible for discussing suicide with fellow students (75\%), believed they had sufficient training (55\%), and felt comfortable discussing suicidal issues with students (60\%). Interestingly, when given the hypothetical situation of dealing with a student who is showing signs of suicide, many students $(36 \%)$ endorsed that they would only be a little likely to raise the question of suicide with them. However, the majority of students also suggested that they would be very likely to encourage the student to get help (68\%) and go with them to get help (48\%).

RAs also reported being sought out for help with over half indicating that peers talk to them about their thoughts and feelings and/or come to them for advice.

\section{Access of Suicide Prevention Materials, Resources, and Referrals}

We also assessed students' perceptions of their college's prevention efforts, including adequacy and knowledge of college and community referral resources. Although the majority of

\section{${ }^{1} 900$ SE Baker Street, A570 McMinnville, OR 97128}

Phone: 503-883-2684

Fax: 503-883-2669

tatompki@linfield.edu 
students' responses reflected familiarity with prevention efforts, there were inconsistencies worth noting. At pre-test, $35 \%$ of students reported that the prevention education materials at their college were present but not well accessed by students, $27 \%$ were unfamiliar with their school's policies regarding suicide, $41 \%$ were unsure of their college's specific plans for helping suicidal students, $11 \%$ did not know where to refer someone who was suicidal, $8 \%$ suggested that they did not have adequate referral resources at their college, $18 \%$ felt like they did not have adequate knowledge of the referral resources at their college, and some noted barrier to referral at their institution (4\%) or within their community $(12 \%)$.

\section{Main Analyses}

In order to evaluate durability of training effects, a series of paired-samples t-tests were conducted revealing positive training effects on many aspects of appraisals. As shown in Table 2, although QPR Quiz Scores showed immediate gains that decreased back to pre-test levels and Self-evaluation of Knowledge showed a significant decline from post-test to follow-up; training effects across all other appraisals were significant and sustained into the next academic term.

A series of repeated-measures ANCOVAs were used to evaluate 6-month prevention outcomes in the sample that completed both baseline and follow-up measures. As shown in Table 3, although there were sustained prevention training gains in RAs appraisals of their preparation, efficacy, knowledge of resources, and intention to intervene with suicidal students, there were no significant gains in $Q P R$ quiz scores or $Q P R$ Behaviors and control group participants also showed gains in some domains (self-evaluation of knowledge, knowledge of resources, gatekeeper efficacy, and general self-efficacy) calling into question the impact of training vs. raising awareness among a trained group of RAs. However, the pattern of results

${ }^{1} 900$ SE Baker Street, A570 McMinnville, OR 97128 Phone: 503-883-2684

Fax: 503-883-2669

tatompki@linfield.edu 
may also reflect a combination of pre-existing between-group differences (controls higher on several variables), limited testing effects, and differential attrition effects (QPR participants who did not complete follow-up assessment reported greater self-perceived knowledge and gatekeeper efficacy). Although there were significant increases in appraisals over time for those who received no training, they tended to be less pronounced than changes in the QPR (see Table 3).

\section{Evaluation of the Program}

Participant evaluations of the QPR training program were generally positive, with the majority (96\%) of participants favorably evaluating the program and most (88\%) feeling it would be of use when helping someone who is suicidal.

\section{Discussion}

The present study is the first to empirically evaluate QPR as a prevention effort with RAs in the college setting. Results indicate that QPR gatekeeper training delivered to RAs resulted in positive proximate outcomes in terms of increasing RAs appraisals of preparation, efficacy, and intentions to perform in a gatekeeper role; nonetheless these changes in appraisals did not translate into sizeable behavior change in terms of self-reported enactment of key gatekeeper behaviors (e.g., asking about suicidal thoughts, convincing a peer to seek help, taking them to a counselor). Although unexpected and counter to desired training outcomes, these results are not entirely inconsistent with other recent studies which have reported limited (e.g., Cross et al., 2007) or relatively modest effects of QPR on increasing self-reported querying of others about suicide (e.g., Wyman et al., 2008). As Cross and colleagues suggest, incorporating skill-based practice into training may enhance skill development. Given RAs high levels of baseline

${ }^{1} 900$ SE Baker Street, A570 McMinnville, OR 97128

Phone: 503-883-2684

Fax: 503-883-2669

tatompki@linfield.edu 
knowledge, appraisals and gatekeeper behaviors, such practice may be particularly important for this select group who may benefit from intensive and focused practice to translate knowledge and appraisals into direct helping behaviors. Wyman and colleagues found evidence supporting a hypothesized gatekeeper communication model whereby strong training effects on asking students about suicide occurred primarily among those staff who, at baseline, were already actively questioning students about suicide and emotional distress. Our own post-hoc analyses suggested that, independent of training, there were significantly fewer RAs that reported at baseline having asked no fellow students about suicide in the past year who, at follow-up, reported asking at least one student about suicide since the last assessment relative to those who consistently asked students about suicide across the two assessment points. As suggested by Wyman et al., in settings with minimal existing preparation, basic gatekeeper training delivered in a universal manner may be of benefit in increasing detection and referral of suicidal students who are displaying clear warning signs of suicide. In other settings, where levels of pre-existing knowledge are already high, focusing on skill training to enhance communication may be more beneficial.

The current results, however, are tempered by measurement issues as the length of time for reporting on key gatekeeper behaviors varied from baseline (i.e., asked within the past year) to follow-up (i.e., asked since the last assessment, which was, on average, 6 months). Ideally the question would have used the same time frame but given the timing of assessment (first month of school after summer break) we felt it advisable to get an estimate of behavior that included the entire prior academic year. Thus, the slight gains are likely an underestimate of changes in key behaviors. Future research will benefit from further exploration of ways to efficiently target

${ }^{1} 900$ SE Baker Street, A570 McMinnville, OR 97128

Phone: 503-883-2684

Fax: 503-883-2669

tatompki@linfield.edu 
type and intensity of training to different constituency groups and to enhance skill development in the college setting. Additionally, obtaining data beyond self-report is critical, including observational data, multiple informants (e.g., questioning residence halls advisees regarding the degree to which they seek help from RAs) and service use data to determine if there are documented increases in referrals by RAs for depression, substance use, and/or suicidality following gatekeeper training.

Significant and sustained changes in appraisals, possible improvements in enacting gatekeeper behaviors, and generally positive evaluations of the program suggest that QPR may be an effective program for colleges to be using. However, changes in appraisals for control group RAs who did not receive training suggest that future research among natural gatekeepers is needed. Program evaluations that incorporate several control conditions, varying role status (e.g., RAs vs. students), duration (e.g., 1-hour vs. 2-day), and format (e.g., didactic vs. experiential practice-based) promise to clarify optimal targeting of training opportunities.

Although some question whether suicide rates are higher among young adults not attending college, many accept that suicide among college students is a problem and data regarding the prevalence of severe depression, suicide ideation and attempts among college students are concerning (ACHA, 2008). Considering multiple risk factors associated with going to college (e.g., leaving home, academic stress, exposure to alcohol/substance use), and the high incidence of diagnosed mental illness among students, it is critically important to promote evidence-based prevention programs in the college setting.

Grosz (1990) suggested that in order for RAs to assist with suicide prevention efforts they must be aware of the behaviors that serve as warning signs. QPR teaches students to identify

\section{${ }^{1} 900$ SE Baker Street, A570 McMinnville, OR 97128}

Phone: 503-883-2684

Fax: 503-883-2669

tatompki@linfield.edu 
behavioral changes and ask those who they may suspect are suicidal directly about possible suicidal ideation. Enhanced detection and questioning, on their own, however, are inadequate and may be detrimental if students are unaware of available resources and/or if referral sources are inadequate to meet the demand for services. Consistent with past research (Furr et al., 2001; Westefeld et al., 2005), we found that the a sizeable minority of the students reported a lack of knowledge regarding prevention resources and services that are available to them, suggesting a need for colleges to educate RAs about where to refer someone who is suicidal. Therefore, colleges must insure the visibility of prevention materials as well as increase student knowledge of resources available to them on and off campus.

It is also imperative that RAs understand their college's policies regarding suicide in order to ease any discomfort in referring a suicidal student for help (Grosz, 1990). However, a substantial number of students in our sample (41\%) were unsure of their school's plans for helping those who were suicidal and some (27\%) suggested that were unfamiliar with their college's policies regarding suicide, suggesting a need for increased education regarding these important aspects of prevention. Given counseling center staff's important role in helping to craft and enact policies and procedures in dealing with suicide attempts and completions (Francis, 2003), gatekeeper training may be enhanced by close collaboration with counseling center staff. Prevention efforts, however, extend well beyond the responsibility of mental health professionals and should involve the entire college community (The Jed Foundation, 2006). A comprehensive and coordinated approach that engages key individuals in the college community to plan, assess, design, implement, and evaluate prevention strategies promises to enhance our understanding of how gatekeeper training fits with other strategies including screening, crisis management, mental

${ }^{1} 900$ SE Baker Street, A570 McMinnville, OR 97128

Phone: 503-883-2684

Fax: 503-883-2669

tatompki@linfield.edu 
health assessment/services, stress management, means restriction, media education, social marketing, and postvention (Suicide Prevention Resource Center, 2004). Given that few students with suicidal ideation access professional services on their own (e.g., Kisch, Leino, \& Silverman, 2005) and that most students report accessing health-related information from parents (75\%), the internet (73\%), health-center staff (59\%), friends (58\%), health educators (54\%), and brochures $(53 \%)$ it is important to consider broadening educational programs like QPR to train other groups of gatekeepers (e.g., all incoming freshman, coaches, faculty, athletic leaders, etc.) and to incorporate information dissemination and screening efforts to include parents and that utilize the internet and/or TV to enhance awareness, identification and referral of potentially suicidal students.

\section{Limitations \& Future Directions}

Although the current study contributes meaningfully to our understanding of the effectiveness of gatekeeper training, several limitations should be noted. The most pronounced limitations involved the use of a quasi-experimental design, limited collection of pre-post data from a comparison group of participants, and differential attrition at 6-month follow-up for QPR and control groups. Although quasi-experimental designs do not afford the same degree of experimental control as randomized clinical trials and therefore cannot rule out several confounds, they can circumvent several practical and ethical constraints that other designs may confront. For instance, we were able to recruit a much larger sample by allowing some degree of choice vs. random assignment and by respecting possible participant burden in our comparison group. Not only did the larger sample provide a more representative look at issues of suicide and

${ }^{1} 900$ SE Baker Street, A570 McMinnville, OR 97128 Phone: 503-883-2684

Fax: 503-883-2669

tatompki@linfield.edu 
suicide prevention, but it also enhanced awareness and engagement of suicide prevention efforts across a more diverse set of campus residence life staffs.

As discussed above, control group participants also demonstrated significant gains across time raising the possible influence of confounds (e.g., testing, regression to the mean) vs. training contributing to change across time. However, QPR participants demonstrated substantial and far-reaching gains suggestive of positive prevention outcomes. These findings are consistent with previous published and unpublished research regarding gatekeeper training and QPR (Shaffer et al, 1988; Stuart, Waalen, Haelstromm., 2003; Davis, 2001; Wyman et al., 2008) suggesting that gains demonstrated in previous studies may extend beyond adolescence.

Choosing appropriate designs for studying suicide prevention is often challenging due to the fact that the chosen design should be both scientifically and ethically sound. One possible solution is using a wait-list control design that allows for an empirical yet ethical evaluation of the prevention program. Brown, Wyman, Guo and Pena (2006) describe the use of a dynamic wait-list design for evaluating QPR in the secondary school setting. Although they describe several benefits, one prominent advantage is that this design allows for more complete saturation of the prevention program which, in turn, may increase the number of referrals (Brown et al., 2006). Ideally future research should extend evaluation efforts in order to determine whether gains are sustained for extended periods of time and whether changes in knowledge, attitudes and beliefs translate into effective intervention. Unfortunately, wait-list control designs, while sensitive to the need to provide suicide prevention training to participating schools, only provide opportunities to examine short term effects and cannot address questions of durability and sustainability of programs (Brown et al., 2006). Needed are studies employing more rigorous

${ }^{1} 900$ SE Baker Street, A570 McMinnville, OR 97128 Phone: 503-883-2684

Fax: 503-883-2669

tatompki@linfield.edu 
designs that evaluate attitudes, beliefs, and knowledge of gatekeeper training participants across time. Further, it is necessary to gather counseling center data to determine if these positive changes in cognitions lead to increased referral and service use on campus.

Although the participants in the current study demonstrated significant gains across a variety of domains, this program was evaluated with a disproportionate number of Caucasian and female participants from small private schools, thus limiting generalizability of results to all college populations. For example, Furr et al. (2001) suggest institutional size may influence the incidence of depression as they found that student's at large universities were more likely to report experiencing depression since coming to college, which in turn could potentially affect the incidence of suicidal ideation and behavior. This issue speaks to the need for collaborative efforts in dissemination and testing of effectiveness across a range of settings.

In summary, this study provides valuable information as the first evaluation of its kind in the college setting and is an important step in understanding the use of QPR and gatekeeper training programs to decrease suicidal ideation, attempts, and completions. The results presented suggest the promise of QPR and its potential impact on the college campuses who adopt it as a prevention method. Future research should aim to monitor counseling center referral data to determine if training is increasing the rate of referral, extend training to additional student populations to evaluate effectiveness among other gatekeepers on campus, and evaluate the fit between the specific type and format of training and effectiveness among different groups of gatekeepers. Although a valuable tool in suicide prevention efforts, QPR training provides only a piece of the suicide prevention puzzle and should be used along with other strategies as a comprehensive and multi-pronged approach for preventing suicide.

${ }^{1} 900$ SE Baker Street, A570 McMinnville, OR 97128

Phone: 503-883-2684

Fax: 503-883-2669

tatompki@linfield.edu 


\section{References}

American College Health Association (2001). American college health association - national college health assessment: Reference group data report fall 2000. Baltimore: American College Health Association.

American College Health Association (2004). Standards of practice for health promotion in higher education. Baltimore, MD: American College Health Task Force on Health Promotion in Higher Education.

American College Health Association (2008). American college health association - national college health assessment: Reference group data report fall 2007. Baltimore: American College Health Association.

Aseltine, R.H., \& DeMartino, R. (2004). An outcome evaluation of the SOS suicide prevention program. American Journal of Public Health, 94, 446-451.

Barrios, L.C., Everett, S.A., Simon, T.R., \& Brener, N.D. (2000). Suicide ideation among U.S. college students: Associations with other injury risk behaviors. Journal of American College Health, 48, 229-233.

Benton, S.A., Robertson, J.M., Tseng, W., Newton, F.B., \& Benton, S.L. (2003).

Changes in counseling center client problems across 13 years. Professional Psychology: Research and Practice, 34, 66-72.

Brener, N., Hassan, S.S., \& Barrios, L.C. (1999). Suicidal ideation among college students. Journal of Consulting and Clinical Psychology, 67, 1004-1008.

Brown, C.H., Wyman, P.A., Guo, J., \& Pena, J. (2006). Dynamic wait-listed designs for

${ }^{1} 900$ SE Baker Street, A570 McMinnville, OR 97128 Phone: 503-883-2684

Fax: 503-883-2669

tatompki@linfield.edu 
randomized trials: New designs for prevention of youth suicide. Clinical Trials, 3, 259271.

Centers for Disease Control and Prevention (2005). WISQARS leading causes of death reports, 2004. Retrieved June 20, 2008, from http://webappa.cdc.gov/sasweb/ncipc/leadcaus10.html

Conner, K.R., \& Goldston, D.B. (2007). Rates of suicide among males increase steadily from age 11-21: Developmental framework and outline for prevention. Aggression and Violent Behavior, 12, 193-207.

Cross, W., Matthieu, M. M., Cerel, J., \& Knox, K. L. (2007). Proximate outcomes of gatekeeper training for suicide prevention in the workplace. Suicide and Life Threatening Behavior, 37, 659-670.

Davis, P. (2001). QPR gatekeeper training results for different age groups. Poster session presented at the meeting of the American Association of Suicidality, Atlanta, GA.

Eggert, L. L., Randell, B. R., Thompson, E. A., \& Johnson, C. L. (1997). Washington state youth suicide prevention program: Report of activities. Seattle, WA: University of Washington.

Francis, P.C. (2003). Developing ethical institutional policies and procedures for working with suicidal students on a college campus. Journal of College Counseling, 6, 114-123.

Furr, S.R., McConnell, G.N, Westefeld, J.S. \& Jenkins, J.M. (2001). Suicide and depression among college students: A decade later. Professional Psychology: Research and Practice, 32, 97-100.

${ }^{1} 900$ SE Baker Street, A570 McMinnville, OR 97128 Phone: 503-883-2684

Fax: 503-883-2669

tatompki@linfield.edu 
Gallagher, R.P., Zhang, B., \& Taylor, R. (2004). National survey of counseling center directors. Alexandria, VA: International Assoication of Counseling Services, Inc.

Garlow, S. J., Rosenberg, J., Moore, J. D., Haas, A. P., Koestner, B., Hendin, H., et al. (2008). Depression, desperation, and suicidal ideation in college students: Results from the American Foundation for Suicide Prevention college screening project at Emory University. Depression and Anxiety, 25, 482-488.

Gould, M.S., Greenberg, T., Munfakh, J.L., Kleinman, M. \& Lubell, K. (2006). Teenagers' attitudes about seeking help from crisis services (hotlines). Suicide and Life-Threatening Behavior, 36, 601-613.

Grosz, R.D. (1990). Suicide: Training the resident assistant as an interventionist. Journal of College Student Psychotherapy, 4, 179-194.

Haas, A.P., Hendin, H., \& Mann, J.J. (2003). Suicide in college students. American Behavioral Scientist, 46, 1224-1240.

The Jed Foundation. (2006). Framework for developing institutional protocols for the acutely distressed or suicidal college student. New York, NY: The Jed Foundation.

Joffe, P. (2008). An empirically supported program to prevent suicide in a college student population. Suicide and Life Threatening Behavior, 38, 87-103.

Kalafat, J., \& Elias, M.J. (1995). Suicide prevention in an educational context: Broad and narrow foci. Suicide and Life-Threatening Behavior, 25, 123-133.

Kaplan, B., \& Reed, M. (2004, Spring). College student mental health: Plan designs, utilization, trends, and costs. Student Health Spectrum, 31-33.

${ }^{1} 900$ SE Baker Street, A570 McMinnville, OR 97128 Phone: 503-883-2684

Fax: 503-883-2669

tatompki@linfield.edu 
King, K. A., \& Smith, J. (2000). Project SOAR: A training program to increase school counselors' knowledge and confidence regarding suicide prevention and intervention. Journal of School Health, 70, 402-407.

Kisch, J., Leino, F. V., \& Silverman, M. M. (2005). Aspects of suicidal behavior, depression, and treatment in college students: Results from the Spring 2000 National College Health Assessment Survey. Suicide and Life-Threatening Behavior, 35, 3-13.

Kitzrow, M.A. (2003). The mental health needs of today's college students: Challenges and recommendations. NASPA Journal, 41, 165-179.

Knox, K.L., Litts, D.A., Talcott, G.W., Feig, J.C. \& Caine, E.D. (2003). Risk of suicide and related adverse outcomes after exposure to a suicide prevention programme in the U.S. Air Force: Cohort study. British Medical Journal, 327, 1376-1378.

Lawrence, M.T. \& Ureda, J.R. (1990). Student recognition of and response to suicidal peers. Suicide and Life-Threatening Behavior, 20, 164-176.

Mann, J. J., Apter, A., Bertolote, J., Beautrais, A., Currier, D., Haas, A. et al. (2005). Suicide prevention strategies: A systematic review. Journal of the American Medical Association, 294, 2064-2074.

Mackesy-Amiti, M. E., Fendrich, M., Libby, S., Goldenberg, D., \& Grossman, J. (1996). Assessment of knowledge gains in proactive training for postvention. Suicide \& LifeThreatening Behavior, 26, 161-174.

Organizational Research Services (2002, July). Youth suicide prevention program. Annual evaluation report 2001-2002. Evaluation of program training workshops. Seattle, WA:

${ }^{1} 900$ SE Baker Street, A570 McMinnville, OR 97128 Phone: 503-883-2684

Fax: 503-883-2669 tatompki@linfield.edu 
Organization Research Services. Retrieved January 6, 2006, from http://www.yspp.org/aboutYSPP/reports/2001-2002Report.pdf

QPR Institute. (2006). QPR gatekeeper training for suicide prevention: The model, rationale and theory. Retrieved May 17, 2007, from http://www.qprinstitute.com/ Ross, C.P. (1980). Mobilizing schools for suicide prevention. Suicide and Life-Threatening Behavior, 10, 239-243.

Shaffer, D., Garland, A., \& Gould, M. (1988). Preventing teenage suicide: A critical review. Journal of the American Academy of Child and Adolescent Psychiatry, 27, 675-687.

Silverman, M.M, Meyer P.M., \& Sloane F. (1997). The big ten-student suicide study: A 10-year study of suicides on midwestern university campuses. Suicide and Life Threatening Behavior, 27, 285-303.

Stuart, C., Waalen, J.K., \& Haelstromm, E. (2003). Many helping hearts: An evaluation of peer gatekeeper training in suicide risk assessment. Death Studies, 27, 321-333.

Suicide Prevention Resource Center (2004). Promoting mental health and preventing suicide in college and university settings. Newton, MA: Education Development Center, Inc.

Tierney, R.J. (1994). Suicide intervention training evaluation: A preliminary report. Crisis: Journal of Crisis Intervention \& Suicide, 15, 69-76.

Turley, B. \& Tanney, B. (1998). LivingWorks Australian Field Trial Evaluation Report on Suicide Intervention Field Trial Australia (SIFTA). Melbourne, Australia: LifeLine Australia.

United States Department of Education - National Center for Education Statistics (2007).

${ }^{1} 900$ SE Baker Street, A570 McMinnville, OR 97128 Phone: 503-883-2684

Fax: 503-883-2669

tatompki@linfield.edu 
Digest of education statistics (NCES 2008-022). Washington D. C. Retrieved July 1, 2008 from http://nces.ed.gov/programs/digest/d07/tables/dt07_182.asp

United States Public Health Service (1999). The Surgeon General's call to action to prevent suicide. Washington D.C. Retrieved May 5, 2007, from http://mentalhealth.samhsa.gov/suicideprevention/calltoaction.asp

Voelker, R. (2003). Mounting student depression taxing campus mental health services. The Journal of the American Medical Association, 286(16), 2055-2056.

Weitzman, E.R. (2004). Poor mental health, depression and associations with alcohol consumption, harm, and abuse in a national sample of young adults in college. The Journal of Nervous and Mental Disease, 192, 269-277.

Westefeld, J.S., Homaifar, B., Spotts, J., Furr, S., Range, L., \& Werth, J.L. (2005). Perceptions concerning college student suicide: Data from four universities. Suicide and Life-Threatening Behavior, 35, 640-645.

Westefeld, J.S., Button, C., Haley, J.T., Kettman, J.J., MacConnell, J., Sandil, R., \& Tallman, B. (2006). College student suicide: A call to action. Death Studies, 30, 931956.

Wyman, P. A., Brown, C. H., Inman, J., Cross, W., Schmeelk-Cone, K., Guo, J. et al. (2008). Randomized trial of a gatekeeper program for suicide prevention: 1-year impact on secondary school staff. Journal of Consulting and Clinical Psychology, 76, 104-115.

${ }^{1} 900$ SE Baker Street, A570 McMinnville, OR 97128

Phone: 503-883-2684

Fax: 503-883-2669

tatompki@linfield.edu 
Table 1

Description of Scales, Items, and Internal Consistency

\begin{tabular}{lll} 
Variable & Items $^{\mathrm{a}}$ & Scale \\
\hline $\begin{array}{l}\text { 14-item QPR } \\
\text { Quiz }\end{array}$ & The number one contributing cause of suicide is ${ }^{\mathrm{b}}$ & Multiple-Choice, T/F
\end{tabular}

\section{Appraisals}

Self-

1. Facts about suicide prevention

Evaluation of 2. Suicide warning signs

Knowledge $^{\mathrm{c}} \quad$ 3. How to ask someone who may be suicidal

4. Persuading someone to get help

5 . How to get help for someone who may be suicidal

6. Information about local resources for help with suicide

7. Please rate your general understanding about suicide and suicide prevention

Knowledge of Resources

1. Are you familiar with your school's policies for helping students contemplating suicide?

2. Is there a specific plan for helping students contemplating suicide at your school?

3. Are suicide prevention education or resource materials available at your school?

4. Do you feel you have adequate referral resources for students contemplating suicide at your college?

5. Do you feel you have adequate knowledge of referral resources
$1=$ Very low to $5=$ Very high

Yes/No

\footnotetext{
${ }^{1} 900$ SE Baker Street, A570 McMinnville, OR 97128
}

Phone: 503-883-2684

Fax: 503-883-2669

tatompki@linfield.edu 
for students contemplating suicide at your college?

${ }^{1} 900$ SE Baker Street, A570 McMinnville, OR 97128

Phone: 503-883-2684

Fax: 503-883-2669

tatompki@linfield.edu 
(Table 1 continued)

Gatekeeper

Efficacy $^{\mathrm{e}}$

Gatekeeper

Reluctance $^{\mathrm{e}}$

1. RAs should not be responsible for discussing suicide

2. If a student experiencing thoughts of suicide does not acknowledge the situation there is very little I can do to help

3. A suicide prevention program in my school will send a message to students that help is available $(\mathrm{R})$

4. If a student contemplating suicide does not seek assistance, there is nothing I can do to help

5. If a student contemplating suicide refuses to seek help it should not be forced upon him/her

6. A suicide prevention program at my school will give students unwanted ideas about suicide

7. I am too busy to participate in suicide prevention activities

8. I cannot understand why a student would contemplate suicide

9. It is important for RAs to report identified cases of suicidal ideation to a specified resource $(\mathrm{R})$
Scale

$\alpha$

1 (Strongly disagree) to 7 (Strongly agree)

1900 SE Baker Street, A570 McMinnville, OR 97128

Phone: 503-883-2684

Fax: 503-883-2669

tatompki@linfield.edu 
(Table 1 continued)

\begin{tabular}{ll} 
Variable & Items \\
\hline Likelihood to & 1. Raise the question of suicide with them \\
Intervene $^{c}$ & 2. Want to get more information about their plan \\
& 3. Encourage them to get help \\
4. Call a crisis line (e.g. 911) to get help \\
5. Go with them to get help (e.g. hospital, mental health center, \\
6. Counselor)
\end{tabular}

General Self-

1. How comfortable would you feel helping someone

efficacy $^{\mathrm{c}}$ who is suicidal?

Scale

2. How confident would you feel helping someone who is suicidal?

3. How competent would you feel helping someone who is suicidal?

\section{Gatekeeper Behaviors}

\begin{tabular}{lll}
\hline Asking the & 1. How many times have you asked a fellow student if s/he was & Open-ended (and dichotomized as Yes/No) \\
Question & considering suicide? & 1 = Never to $5=$ Always \\
QPR & For every peer identified how often have you... & \\
Behaviors & 1. Asked the student about suicidal thoughts & \\
& 2. Spent some time listening to the student & \\
& 3. Provided appropriate information & \\
& 4. Convince the student to week help \\
& 5. Taken a student to the counselor or other resource \\
& 6. Notified appropriate referral resources \\
\hline
\end{tabular}

\footnotetext{
${ }^{1} 900$ SE Baker Street, A570 McMinnville, OR 97128
}

Phone: 503-883-2684

Fax: 503-883-2669

tatompki@linfield.edu 
7. Other:

${ }^{1} 900$ SE Baker Street, A570 McMinnville, OR 97128

Phone: 503-883-2684

Fax: 503-883-2669

tatompki@linfield.edu 


\section{Evaluation of Training}

Variable Items

Scale

\section{Overall}

Evaluation of

QPR

Usefulness of

QPR

1. What is your overall evaluation of the training session?

1. Do you believe this training will help you in helping someone who is suicidal?
$1=$ Poor to $5=$ Excellent

Yes/No/Unsure

Note. R indicates that this item was reverse scored prior to averaging. For all domains involving multiple items, final scores represent average ratings across all items.

${ }^{\mathrm{a}}$ A copy of all study-related materials may be obtained from the second author. ${ }^{\mathrm{b}}$ Contact the QPR Institute for a complete measure of the QPR Knowledge Quiz (http://www.qprinstitute.com/). ${ }^{\mathrm{c}}$ Items on these scales were adapted from tools developed by the Organizational Research Services to evaluate Youth Suicide Prevention Program in Washington. ${ }^{\mathrm{d}}$ All but last item on this scale replicates Wyman et al.'s (2008) Access to Services scale. 'Items on both scales replicate Wyman et al.'s Gatekeeper Efficacy and Gatekeeper Reluctance scales.

${ }^{1} 900$ SE Baker Street, A570 McMinnville, OR 97128

Phone: 503-883-2684

Fax: 503-883-2669

tatompki@linfield.edu 
Table 2

QPR Participants' Average Change in Knowledge, Appraisals, and Behavior Across Pre-test, Post-test, and Follow-up Assessments

\begin{tabular}{lllllllll}
\multirow{2}{*}{ Domain } & \multicolumn{2}{c}{ Pre-Test } & & \multicolumn{2}{c}{ Post-Test } & & \multicolumn{2}{c}{ Follow-up } \\
\cline { 2 - 3 } & Mean & SD & & Mean & SD & & Mean & SD \\
\hline QPR Quiz - Percent & $71.30_{\mathrm{a}}$ & .13 & & $85.21_{\mathrm{b}}$ & .11 & & $72.93_{\mathrm{a}}$ & .14
\end{tabular}

Appraisals

$\begin{array}{lcccccc}\text { Self-Evaluation of Knowledge } & 2.86_{\mathrm{a}} & .58 & 3.94_{\mathrm{b}} & .48 & 3.71_{\mathrm{c}} & .51 \\ \text { Knowledge of Resources } & .51_{\mathrm{a}} & .32 & .88_{\mathrm{b}} & .17 & .91_{\mathrm{b}} & .17 \\ \text { Gatekeeper Efficacy } & 4.23_{\mathrm{a}} & .73 & 5.24_{\mathrm{b}} & .65 & 5.11_{\mathrm{b}} & .64 \\ \text { Gatekeeper Reluctance } & 2.74_{\mathrm{a}} & .77 & 2.32_{\mathrm{b}} & .65 & 2.46_{\mathrm{b}} & .66 \\ \text { Likelihood to Intervene } & 3.64_{\mathrm{a}} & .60 & & & 4.05_{\mathrm{b}} & .58 \\ \text { General Self-Efficacy } & 3.23_{\mathrm{a}} & .80 & 3.85_{\mathrm{b}} & .61 & 3.69_{\mathrm{b}} & .70\end{array}$

Gatekeeper Behaviors $^{\mathrm{a}}$

$\begin{array}{llllll}\text { Ask About Suicide } & .39 & 1.15 & .46 & 1.10 \\ \text { QPR Behaviors } & 2.68 & .88 & 3.04 & 1.11\end{array}$

\footnotetext{
Note. Due to problems with post-test data collection items assessing appraisals related to Likelihood to Intervene were not available at post-test and items assessing key gatekeeper behaviors were only appropriately asked at baseline and follow-up. Means in the same row that do not share a subscript are significantly different at $p<.05$.

${ }^{a}$ Although there were no significant gains in key gatekeeper behaviors from baseline to followup, it should be noted that the length of time to engage in gatekeeper behaviors was dramatically shorter (on average 6 months) as compared to reporting on frequency of behaviors in the past year. Ideally the question would have used the same time frame but given timing of assessment (first month of school after summer break) we felt it advisable to get an estimate of behavior that included the entire prior academic year. Thus, the slight gains are likely an underestimate of changes in key behaviors.
}

${ }^{1} 900$ SE Baker Street, A570 McMinnville, OR 97128

Phone: 503-883-2684

Fax: 503-883-2669

tatompki@linfield.edu 
Table 3

Repeated Measures Analyses of Variance (ANOVA) Results Exploring Follow-up Prevention Outcomes Across Groups

\begin{tabular}{|c|c|c|c|c|}
\hline \multirow[b]{2}{*}{ Variable } & \multirow{2}{*}{$\begin{array}{c}\text { QPR } \\
\text { Participants } \\
M(S D)\end{array}$} & \multirow{2}{*}{$\begin{array}{c}\begin{array}{c}\text { Control } \\
\text { Participants }\end{array} \\
M(S D)\end{array}$} & \multicolumn{2}{|c|}{$F$} \\
\hline & & & Time & Interaction \\
\hline QPR Quiz - Percent & & & 2.50 & .01 \\
\hline Pre-test & $70.15(.14)$ & $72.70(.12)$ & & \\
\hline Follow-up & $70.91(.12)$ & $71.78(.14)$ & & \\
\hline \multicolumn{5}{|l|}{ Appraisals } \\
\hline Self-Evaluation of Knowledge & & & $94.57 * * *$ & $11.32 * * *$ \\
\hline Pre-test & $2.82(.58)_{a}$ & $3.23(.71)_{\mathrm{a}}$ & & \\
\hline Follow-up & $3.68(.49)_{\mathrm{b}}$ & $3.51(.45)_{b}$ & & \\
\hline Knowledge of Resources & & & $105.84 * * *$ & $40.56 * * *$ \\
\hline Pre-test & $.49(.33)_{\mathrm{a}}$ & $.75(.25)_{\mathrm{a}}$ & & \\
\hline Follow-up & $.91(.15)_{\mathrm{b}}$ & $.85(.21)_{\mathrm{b}}$ & & \\
\hline Gatekeeper Efficacy & & & $32.32 * * *$ & $10.59 * * *$ \\
\hline Pre-test & $4.17(.70)_{\mathrm{a}}$ & $4.47(.78)_{\mathrm{a}}$ & & \\
\hline Follow-up & $5.06(.66)_{b}$ & $4.81(.58)_{b}$ & & \\
\hline Gatekeeper Reluctance & & & $3.75 *$ & .34 \\
\hline Pre-test & $2.75(.83)_{\mathrm{a}}$ & $2.71(.96)$ & & \\
\hline Follow-up & $2.47(.64)_{b}$ & $2.62(.67)$ & & \\
\hline Likelihood to Intervene & & & $6.82 * *$ & $6.53 *$ \\
\hline Pre-test & $3.63(.61)_{\mathrm{a}}$ & $3.71(.60)$ & & \\
\hline
\end{tabular}

${ }^{1} 900$ SE Baker Street, A570 McMinnville, OR 97128

Phone: 503-883-2684

Fax: 503-883-2669

tatompki@linfield.edu 
Follow-up

$4.07(.60)_{b}$

$3.72(.66)$

${ }^{1} 900$ SE Baker Street, A570 McMinnville, OR 97128 Phone: 503-883-2684

Fax: 503-883-2669

tatompki@linfield.edu 
Gatekeeper Training 38

(Table 3 continued)

\begin{tabular}{|c|c|c|c|c|}
\hline \multirow[b]{2}{*}{ Variable } & \multirow{2}{*}{$\begin{array}{c}\begin{array}{c}\text { QPR } \\
\text { Participants }\end{array} \\
M(S D)\end{array}$} & \multirow{2}{*}{$\begin{array}{c}\begin{array}{c}\text { Control } \\
\text { Participants }\end{array} \\
M(S D)\end{array}$} & \multicolumn{2}{|c|}{$F$} \\
\hline & & & Time & Interaction \\
\hline General Self-Efficacy & & & $36.13^{* * *}$ & .53 \\
\hline Pre-test & $3.27(.77)_{\mathrm{a}}$ & $3.38(.81)_{\mathrm{a}}$ & & \\
\hline Follow-up & $3.68(.70)_{b}$ & $3.63(.58)_{b}$ & & \\
\hline Gatekeeper Behaviors $^{\mathrm{a}}$ & & & & \\
\hline Ask About Suicide & & & .44 & .07 \\
\hline Pre-test & $.44(1.22)$ & $.50(.93)$ & & \\
\hline Follow-up & $.49(1.14)$ & $.53(.96)$ & & \\
\hline QPR Behaviors & & & $4.71^{*}$ & .26 \\
\hline Pre-test & $2.73(.90)$ & $3.00(.96)$ & & \\
\hline Follow-up & $3.09(1.10)$ & $3.11(.90)$ & & \\
\hline
\end{tabular}

Note. Means in the same column that do not share subscripts differ at $p<.05$ according to posthoc paired samples t-tests.

$* p<.05 . * * p<.001 . * * * p<.001$.

${ }^{1} 900$ SE Baker Street, A570 McMinnville, OR 97128

Phone: 503-883-2684

Fax: 503-883-2669

tatompki@linfield.edu 